\title{
COVID-19 NAS PRISÕES BRASILEIRAS: UMA ANÁLISE SOB A ÉGIDE DA CULTURA DO ENCARCERAMENTO
}

\author{
COVID-19 IN BRAZILIAN PRISIONS: AN ANALYSIS UNDER THE AEGIS OF THE \\ INCARCERATION CULTURE
}

DOI: http://dx.doi.org/10.16891/2317-434X.v8.e3.a2020.pp757-765 Recebido em: 31.07.2020 | Aceito em: 15.10.2020

Ana Laura Piasea*a, Suzana Cysneiros Sampaiob, Carla Pedrosa de Figueiredoa

Universidade Federal de Campina Grande - UFCGa

Centro Universitário Doutor Leão Sampaiob

*E-mail: laurapdie@gmail.com

\section{RESUMO}

O trabalho ora apresentado destina-se à análise do sistema prisional brasileiro em tempos de pandemia, com isto, buscou-se problematizar a influência que a cultura do encarceramento exerce nesse cenário. A investigação justificase pela importância de fomentar discussões sobre os impactos da COVID-19 no âmbito dos presídios brasileiros, haja vista a atualidade e urgência desse debate. Portanto, o objetivo geral do estudo foi identificar e discorrer a respeito dos principais obstáculos enfrentados pelas prisões no combate ao coronavírus. Para tanto, a metodologia utilizada pauta-se nos métodos de abordagem dedutivo e qualitativo, auxiliados pelas técnicas de pesquisa bibliográfica e de análise documental. Destarte, os resultados do exame realizado apontam que o sistema penitenciário do Brasil sofre com um acentuado déficit de vagas e superlotação, o que pode dificultar a aplicação adequada das medidas recomendadas pelas autoridades para reduzir a disseminação da COVID-19 nos estabelecimentos penais. Tal situação é fomentada pela cultura do encarceramento, tendo em vista que as propostas de desencarceramento ainda são adotadas de forma tímida entre os magistrados brasileiros, do mesmo modo, são amplamente criticadas pela sociedade, a qual entende que o encarceramento representa a solução mais adequada no que se refere ao controle da criminalidade.

Palavras-chave: Coronavírus; estabelecimentos penais; superlotação.

\section{ABSTRACT}

The work presented here is intended for the analysis of the brazilian prison system in times of pandemic, with this, we sought to problematize the influence that the culture of incarceration has in this scenario. The investigation is justified by the importance of fostering discussions about the impacts of COVID-19 in the context of brazilian prisons, given the current and urgent nature of this debate. Therefore, the general objective of the study was to identify and discuss the main obstacles faced by prisons in the fight against coronavirus. To this end, the methodology used is based on the deductive and qualitative approach methods, aided by bibliographic research and document analysis techniques. Thus, the results of the examination indicate that the brazilian prison system suffers from a marked deficit of vacancies and overcrowding, which may hinder the proper application of the measures recommended by the authorities to reduce the spread of COVID-19 in criminal establishments. This situation is fostered by the culture of incarceration, considering that the proposals for incarceration are still adopted timidly among brazilian magistrates, likewise, they are widely criticized by society, which believes that incarceration represents the most appropriate solution with regard to the control of crime.

Keyword: Coronavirus; criminal establishments; overcrowded. 


\section{INTRODUÇÃO}

A Constituição Federal de 1988 consolida em seu artigo 196 o direito à saúde, transferindo para o Estado o dever de assegurá-la a todos os cidadãos. Posto isto, com a chegada da pandemia do novo coronavírus (2019-nCov) no Brasil, doença altamente contagiosa e responsável por causar quadros graves de insuficiência respiratória, a sociedade tem esperado respostas estatais que minimizem os resultados acarretados pelas crises de ordem econômica, política e de saúde pública instauradas, inclusive no âmbito do sistema penitenciário nacional, o qual já vem enfrentando uma crise de natureza estrutural que decorre, dentre outros fatores, da superpopulação de pessoas privadas de liberdade.

Diante disso, o presente artigo científico tem por escopo refletir sobre a COVID-19 nas prisões, bem como, realizar uma análise crítica da temática pautada nos impactos que a cultura do encarceramento exerce no combate ao coronavírus. Sendo assim, o problema de pesquisa ora em discussão emana do seguinte questionamento: Em que medida a cultura do encarceramento representa um obstáculo ao enfrentamento do novo coronavírus no âmbito das unidades que compõem o sistema penitenciário nacional?

Destarte, a investigação do objeto de estudo ora em epígrafe justifica-se, em âmbito teórico, por tratar de uma questão atual e urgente, a qual solicita maiores esclarecimentos. Frise-se, aliás, que a análise das metodologias empregadas no combate à COVID-19 dentro das prisões deve estar alinhada às reflexões de ordem jurídica. Ademais, utilizando-se como parâmetro a própria cultura do encarceramento, que se faz presente não só na sociedade brasileira, como também exerce grande influência no Direito Processual Penal brasileiro, é possível identificar em que grau as políticas públicas de saúde podem apresentar eficácia satisfatória, tendo em vista que os problemas estruturais dos presídios podem dificultar a aplicação de tais diligências.

Nesse seguimento, o trabalho científico aqui exposto tem como objetivo geral realizar uma abordagem a respeito dos efeitos negativos que a cultura do encarceramento perpetra sob as ações de enfrentamento ao novo coronavírus na atual conjuntura do sistema prisional brasileiro. Em contrapartida, o exame pretende como objetivos específicos, identificar os conceitos mais relevantes à compreensão do tema; fazer uma análise qualitativa sobre os dados da população carcerária do Brasil e; discorrer sobre a cultura do encarceramento.

O tema abordado será desenvolvido ao longo de três tópicos fundamentais para que a investigação seja apresentada de forma didática. Sendo assim, o primeiro tópico trará alguns conceitos e dados oficiais sobre a situação atual do sistema penitenciário do Brasil. Em seguida, o segundo tópico realizará uma abordagem aprofundada sobre as repercussões da COVID-19 nas prisões do Brasil, destacando os principais textos legais que versam sobre as medidas de enfrentamento ao novo coronavírus nos estabelecimentos penais. Finalmente, o terceiro tópico versará sobre o paradigma da cultura do encarceramento e como isso afeta o direito de assistência à saúde das pessoas privadas de liberdade no atual cenário de pandemia.

\section{METODOLOGIA}

O presente trabalho é uma revisão bibliográfica narrativa, de caráter básico, pautada na pesquisa e leitura de estudos já publicados sobre o tema proposto, selecionados subjetivamente pelas autoras, de forma não exaustiva.

Destarte, para atingir os objetivos tracejados, a presente pesquisa foi produzida por meio do método de abordagem qualitativo, em conjunto com a análise dedutiva, o que se demonstrou importante para a realização de um estudo dos dados oficiais disponibilizados por órgãos governamentais sobre a realidade do sistema penitenciário do Brasil. Ademais, foram utilizadas as técnicas de pesquisa bibliográfica, por meio da leitura de livros, doutrinas jurídicas e artigos científicos, complementada pela análise documental, realizada através da consulta de parte fundamental da legislação voltada para o assunto em tela.

\section{ASPECTOS GERAIS DO SISTEMA PRISIONAL BRASILEIRO}

O sistema prisional brasileiro teve seus delineamentos iniciais a partir da construção das primeiras unidades destinadas ao cumprimento de penas restritivas de liberdade, as chamadas cadeias públicas, as quais começaram a ser edificadas no século XIX e buscavam possibilitar o cumprimento das penas de prisão previstas no Código Criminal do Império de 1830, assim dizendo, a prisão simples e a prisão com trabalho, admitindo-se a prisão perpétua com trabalho. Posteriormente, com o Código Penal de 1890, as prisões passaram a comportar celas individuais e oficinas de trabalho e foram estabelecidos novos tipos de prisão, quais sejam, prisão celular, reclusão, prisão com trabalho obrigatório e prisão disciplinar. Nesse cenário, foram excluídas as penas de caráter perpétuo ou coletivo, de modo que o texto legal se limitou às penas restritivas de liberdade individual, com caráter temporário e pelo período máximo de trinta anos (MACHADO; SOUZA; SOUZA, 2013, p. 3).

Portanto, partindo do pressuposto de que a noção de sistema penitenciário está historicamente relacionada com a viabilização do cumprimento das penas restritivas 
de liberdade no Brasil, pode-se afirmar que, atualmente, ele representa o conjunto de estabelecimentos destinados ao cumprimento de sentenças que imponham ao réu uma sanção penal de caráter privativo de liberdade, as quais poderão ser estabelecidas em regime fechado, semiaberto e aberto. Aliás, essas unidades subdividem-se em femininas e masculinas e incluem os locais onde são mantidos os presos provisórios, isto é, os estabelecimentos penais.

Atualmente, a legislação penal brasileira prevê os denominados estabelecimentos penais que, nos termos do artigo 82 da Lei federal nº 7.210, de 11 de julho de 1984 , nomeada Lei de Execução Penal - LEP, “destinam-se ao condenado, ao submetido à medida de segurança, ao preso provisório e ao egresso". Nesse sentido, o artigo 83 assevera ainda que "o estabelecimento penal, conforme a sua natureza, deverá contar em suas dependências com áreas e serviços destinados a dar assistência, educação, trabalho, recreação e prática esportiva" (BRASIL, 1984).

$\mathrm{O}$ termo estabelecimento penal refere-se aos diferentes espaços de custódia que compõe o sistema penitenciário do Brasil, quais sejam, as penitenciárias, as colônias penais agrícola, industrial ou similar, as casas do albergado, os Centros de Observação Criminológica ${ }^{1}$, os hospitais de custódia e tratamento psiquiátrico e as cadeias públicas. Assim sendo, de acordo com a LEP, as penitenciárias são designadas ao abrigo de presos submetidos a pena de reclusão em regime fechado, as colônias penais destinam-se ao cumprimento de pena em regime semiaberto e as casas do albergado se reservam ao cumprimento da pena em regime aberto, incluindo-se a pena de limitação de fïm de semana.

Os hospitais de custódia e tratamento psiquiátrico, por seu turno, têm como finalidade o abrigo de indivíduos submetidos a medida de segurança de internação. Finalmente, as cadeias públicas são os locais destinados ao recolhimento de presos provisórios, uma vez que estes devem permanecer separados dos presos já condenados definitivamente. Vale frisar nesse ponto que, atualmente, há os centros de detenção provisória, com estrutura similar a dos presídios e um maior número de vagas, voltados exclusivamente aos presos provisórios. Diferentemente das cadeias públicas, nos centros de detenção provisória podem ser desenvolvidas atividades diversas pelos detentos, inclusive o trabalho (NUCCI, 2019, p. 142).

${ }^{1}$ Os Centros de Observação Criminológica são previstos pela LEP em seus arts. 96 a 98 e têm como finalidade a realização de exames gerais, bem como o exame criminológico, cujos resultados deverão ser encaminhados à Comissão Técnica de Classificação. Os Centros de Observação podem ser instalados em unidades autônomas ou em anexos aos estabelecimentos penais.
Dito isto, infere-se que o sistema prisional compõe um conjunto de institutos que juntos possibilitam o exercício da pretensão punitiva estatal ante a prática de atos considerados pela lei penal como delituosos e, por essa razão, puníveis com a cominação legal de uma pena. Em tais estabelecimento deve ser promovida atividades que busquem a recuperação do transgressor, a fim de que ao término de sua pena, ele possa retornar ao convívio social. Sendo assim, esse sistema representa uma importante expressão da política criminal $^{2}$ desenvolvida pelos Estados.

No Brasil, a legislação penal estabelece duas espécies de sanção penal, a pena e a medida de segurança. A pena, por seu modo, subdivide-se em privativas de liberdade, restritivas de direitos e de multa, consoante o disposto no artigo 32 do Código Penal. Isto posto, sustenta-se que a pena representa, dentro da estrutura do Estado, uma forma de controle social, sendo justificável na medida de sua necessidade (BITENCOURT, 2020, p. 146-147), caracterizando-se por ser uma sanção de caráter aflitivo imposta pelo Estado e direcionada ao autor da conduta delituosa, como forma de retribuição e, ainda, com o escopo de que não pratique novos delitos (JESUS, 2020, p. 541).

Portanto, o sistema prisional brasileiro tem um importante papel na fase de execução penal, devendo zelar por um ambiente que possibilite que a sanção penal não só promova o castigo e a intimidação, mas seja um instrumento ressocializador. Nesse prisma, o artigo $10 \mathrm{da}$ LEP, determina que "a assistência ao preso e ao internado é dever do Estado, objetivando prevenir o crime e orientar o retorno à convivência em sociedade" (BRASIL, 1984).

Consoante o artigo 11 da LEP, a assistência aos presos, internados e egressos no âmbito das unidades componentes do sistema penitenciário nacional deve atender necessidades de ordem material, de saúde, jurídica, educacional, social e religiosa. No entanto, conforme dados oficiais, o estado atual das unidades prisionais do país não tem sido capaz de oferecer uma assistência adequada aos custodiados, especialmente no que tange à saúde.

Segundo o Levantamento Nacional de Informações Penitenciárias - Infopen, organizado pelo Departamento Penitenciário Nacional - $\mathrm{DEPEN}^{3}$, no segundo semestre de 2019 o número de pessoas que

${ }^{2}$ A política criminal de um Estado "é um modo de raciocinar e estudar o direito penal [...] visando à criação de novos institutos jurídicos que possam satisfazer as finalidades primordiais de controle social desse ramo do ordenamento" (NUCCI, 2019, p. $80)$. 
cumpriam algum tipo de pena restritiva de liberdade ou medida de segurança no Sistema Penitenciário Federal e Estadual, era de 748.009 (BRASIL, 2020b, p. 2-3). Desse total, $95,06 \%$ eram indivíduos do sexo masculino e 4,94\% do sexo feminino (BRASIL, 2020b, p. 14). Ressalte-se que, incluídos os dados sobre a polícias judiciárias e batalhões de polícias e bombeiros militares, a totalidade de pessoas privadas de liberdade no país chegava a 755.274 (BRASIL, 2020b, p. 4).

Analisando-se o total da população carcerária brasileira em unidades do Sistema Prisional Estadual e Federal pela natureza da prisão e o tipo de regime penal, constata-se que $362.547(48,47 \%)$ pessoas estão submetidas ao regime fechado, enquanto que 222.558 (29,75\%) correspondem a presos provisórios, isto é, indivíduos sem sentença criminal condenatória transitada em julgado, seguidos por 133.408 (17,84\%) pessoas cumprindo pena em regime semiaberto e $25.137(3,36 \%)$ no regime aberto (BRASIL, 2020b, p. 2-3).

Nesse cenário, ao se comparar o número de pessoas privadas de liberdade no Sistema Penitenciário Estadual e Federal e em outras prisões (755.274) com o número de vagas disponíveis nas unidades prisionais (442.348), percebe-se que há um déficit total de 312.925 vagas (BRASIL, 2020b, p. 7). Aliás, até dezembro de 2019, a taxa de aprisionamento ${ }^{4}$ era de 359,40 pessoas custodiadas para cada 100 mil habitantes no Brasil (BRASIL, 2020b, p.7).

Ademais, o Infopen de 2019 também atualizou dados sobre a assistência aos presos e aos internados, prevista no artigo 11 da LEP. Destarte, no que se refere à saúde no âmbito dos presídios brasileiros, foram dispostas informações sobre a estrutura física das unidades, os profissionais da saúde que atendem os encarcerados, os procedimentos médicos realizados, as doenças identificadas e as taxas de mortalidade dos estabelecimentos penais. Todavia, os dados apresentados pela pesquisa não demonstraram o percentual quantitativo de indivíduos encarcerados com acesso à estrutura adequada aos serviços de saúde. Não obstante, vale ressaltar que, segundo o Infopen de 2017, esse percentual

${ }^{3} \mathrm{O}$ DEPEN é um órgão executivo da Política Penitenciária Nacional com status de Secretaria Nacional, subordinado ao Ministério da Justiça, responsável por, dentre outras atribuições, fiscalizar a adequada aplicação da LEP e das diretrizes da Política Penitenciária Nacional. Pontue-se que o órgão tem o dever de "inspecionar e fiscalizar periodicamente os estabelecimentos e serviços penais" (BRASIL, 1984).

${ }^{4} \mathrm{~A}$ taxa de aprisionamento é calculada pela razão entre a totalidade de indivíduos privados de liberdade e o valor populacional do país, de modo que a razão obtida é multiplicada por 100 mil (MOURA, 2017, p. 12).

${ }^{5}$ No Brasil, essas informações são disponibilizadas oficialmente pela OMS em conjunto com Organização Pan-Americana da era de $66,7 \%$ do total das pessoas privadas de liberdade (MOURA, 2019, p. 51).

Enfim, com base no exposto, infere-se que o sistema penitenciário brasileiro passa por um momento de crise, o que nos permite questionar sobre a viabilidade da assistência prevista nos artigos 10 e 11 da LEP, especialmente quando se tratam de questões de saúde. Sendo assim, torna-se imprescindível a abordagem da disseminação da COVID-19 dentro dos ambientes carcerários do Brasil, bem como, a análise das ações que o Poder Público tem tomado com o objetivo de minimizar os impactos causados pelo coronavírus nas prisões, as quais já sofrem com problemas graves causados pela superpopulação, insalubridade e dificuldades em garantir assistência à saúde adequadamente às pessoas privadas de liberdade.

\section{REPERSCUSSÕES DA COVID-19 NOS PRESÍDIOS BRASILEIROS}

No dia 31 de dezembro de 2019 a Organização Mundial da Saúde - OMS foi notificada a respeito da ocorrência de diversos casos identificados como pneumonia, na cidade de Wuhan, província de Hubei, na República Popular da China. No entanto, no dia 7 de janeiro de 2020, veio a confirmação pelas autoridades chinesas de que, na verdade, tratava-se de um novo tipo de coronavírus, o qual recebeu o nome de SARS-CoV-2 e é responsável por causar a Corona Virus Dicease - 2019, conhecida comumente pela sigla COVID-19 5

Ressalte-se que a COVID-19 desencadeou uma crise mundial sem precedentes no século XXI, tendo sido apontada pela OMS como uma Emergência de Saúde Pública de Importância Internacional - ESPII. Ademais, devido à sua rápida disseminação em diferentes países, o surto da doença recebeu o status de pandemia. No Brasil, o primeiro caso da doença foi confirmado pelo Ministério da Saúde em 25 de março de 2020. Atualmente, até dia 31 de julho de 2020, já foram acumulados 2.662.485 casos confirmados e 92.475 óbitos por COVID-19 no Estado brasileiro $^{6}$, o que representa um cenário preocupante

Saúde - OPAS, atuante em alguns países da América do Sul. Disponível em: https://www.paho.org/bra/index.php?option=com_content\&vie $\mathrm{w}=$ article $\& \mathrm{id}=6101$ : $\operatorname{covid} 19 \&$ Itemid=875. Acesso em: $31 \mathrm{jul}$. 2020.

${ }^{6}$ Os dados oficiais sobre o avanço e a totalidade dos casos da COVID-19 nos estados do Brasil, assim como o número de óbitos e recuperações, são atualizados e disponibilizados diariamente pelo Ministério da Saúde. Disponível em: http://susanalitico.saude.gov.br/\#/dashboard/. Acesso em: 31 jul. 2020 . 
gerador de graves crises de ordem econômica, política e de saúde pública.

Diante da situação instaurada pela pandemia do novo coronavírus no Brasil, no dia 3 de fevereiro de 2020 , o Ministério da Saúde editou a Portaria $n^{\circ} 188$ a qual declarou que o surto causado pela COVID-19 representava uma Emergência em Saúde Pública de Importância Nacional - ESPIN (BRASIL, 2020h). Em seguida, no que tange a adoção de medidas pelas autoridades públicas ao enfrentamento de tal situação, foi sancionada a Lei federal n. 13.979, de 06 de fevereiro de 2020, que dispõe, entre outras medidas, sobre a possibilidade de as autoridades, no âmbito de suas competências, adotarem o isolamento e a quarentena (BRASIL, 2020e). Outrossim, no dia de 20 de março, por meio do Decreto Legislativo $n^{\circ} 6$, de 2020 , foi reconhecida pelo Congresso Nacional a ocorrência do estado de calamidade pública no Brasil, com efeitos que deverão perdurar até dia 31 de dezembro de 2020 (BRASIL, 2020a).

No âmbito do sistema penitenciário nacional, entre os documentos legais editados em atenção ao combate da COVID-19, houve a regulamentação da Portaria Interministerial $n^{\circ} 7$, de 18 de março de 2020, a qual desatentando-se à realidade manifesta da superlotação e insalubridade das unidades prisionais nacionais, orienta a Administração Penitenciária no sentido de isolamento individual, na hipótese de identificação de casos suspeitos ou confirmados. Nesse sentido, consoante o $\S 1^{\circ}$ do artigo $3^{\circ}$ da supracitada Portaria Interministerial:

Caso não seja possível o isolamento em cela individual dos casos suspeitos ou confirmados, recomenda-se à Administração Penitenciária adotar o isolamento por corte e o uso de cortinas ou marcações no chão para a delimitação de distância mínima de dois metros entre os custodiados (BRASIL, 2020g).

Ademais, a Portaria Interministerial elenca, em seu artigo $6^{\circ}$, medidas restritivas quanto à visita e acesso das pessoas da sociedade externa, determinando em seu parágrafo único que nos Estados em que houver confirmação de caso de COVID-19, a Administração Penitenciária será responsável por avaliar a proibição de entrada de visitantes que se enquadrem como grupo de risco, quais sejam, pessoas acima de 60 (sessenta anos), com doenças crônicas ou respiratórias, gestantes ou crianças menores de 05 (cinco) anos (BRASIL 2020g). Todavia, ressalte-se que, tais medidas reducionistas e suspensivas acabam sendo direcionadas, primordialmente, a proteção da saúde de membros da sociedade externa.

Ainda sobre as medidas preventivas contra a disseminação da COVID-19, o Conselho Nacional de Justiça - CNJ também se posicionou através da
Recomendação $n^{\circ}$ 62, a qual é direcionada especificamente à prevenção no contexto dos estabelecimentos que compõe os sistemas prisional e socioeducativo do Brasil. Vale pontuar que a Recomendação do CNJ é medida de aplicação temporária, enquanto perdurar os efeitos da pandemia causada pela COVID-19 na sociedade brasileira.

No que tange ao sistema prisional, a Recomendação do CNJ direciona-se à mitigação do rigor da prisão em dois momentos distintos, ao momento anterior a fase de execução penal e quando o indivíduo já estiver efetivamente cumprindo a sentença condenatória. Entre as providências a serem adotadas pelos magistrados, recomenda o artigo $4^{\circ}$, inciso I, que os magistrados com competência para a fase de conhecimento criminal considerem "a reavaliação das prisões provisórias, nos termos do artigo 316, do Código de Processo Penal" (CNJ, 2020), devendo-se priorizar um determinado grupo de pessoas. Ademais, o inciso II do artigo $4^{\circ}$ prevê a possibilidade de adoção pelos magistrados da "suspensão do dever de apresentação periódica ao juízo das pessoas em liberdade provisória ou suspensão condicional do processo, pelo prazo de 90 (noventa) dias" (CNJ, 2020), enquanto que o inciso III do mesmo dispositivo recomenda que as novas ordens de prisão preventiva sejam decretadas em caráter excepcional (CNJ, 2020).

Dando continuidade, a Recomendação do CNJ determina, em seu artigo $5^{\circ}$, que sejam consideradas pelos magistrados com competência sobre a execução penal a adoção de algumas medidas, como por exemplo a possibilidade de concessão de saída antecipada dos regimes fechado e semiaberto e a concessão de prisão domiciliar para substituir os regimes aberto e semiaberto. Frise-se que essas recomendações somente se aplicam a um grupo de pessoas e/ou em casos restritos. Além disso, tais proposições elencadas nos incisos do artigo $5^{\circ}$ da Recomendação e têm como finalidade tão somente promover a "redução dos riscos epidemiológicos e em observância ao contexto local de disseminação do vírus" (CNJ, 2020).

Portanto, embora a Recomendação do CNJ seja direcionada para a prevenção de infecção pela COVID-19 nos estabelecimentos prisionais, a sua aplicação encontra resistência por parte dos magistrados brasileiros. Nesse sentido, registre-se que, segundo estudos disponibilizados pela Coordenação de Pesquisas da Defensoria Pública de São Paulo - DPE/SP, no Estado de São Paulo, onde se encontra a maior população carcerária do país, 231.287 pessoas do total, até o dia 31 de julho de 2020, apenas $3,66 \%$ dos processos que se enquadravam nas hipóteses de relaxamento de prisão, previstas na Recomendação, receberam alvará de soltura, assim, dos 29.129 processos movimentados nesse período, apenas 1.064 alvarás foram expedidos (SÃO PAULO, 2020). 
O DEPEN, no que lhe concerne, também teve participação nas propostas de combate e prevenção à COVID-19 nas penitenciárias brasileiras. Tal órgão aconselhou a utilização de estruturas e instalações temporárias para os presos com suspeita de infecção pela COVID-19, sendo que, essas instalações seriam aos moldes de um contêiner (BRASIL, 2020d). Porém, a proposta foi duramente criticada por órgãos e entidades que se empenham no estudo de impactos do desenvolvimento de políticas criminais. $O$ ofício que tratava da temática foi encaminhado ao Conselho Nacional de Política Criminal e Penitenciária - CNPCP, o qual rejeitou a proposta.

Não obstante, o CNCPC editou a Resolução $n^{\circ} 5$, de 15 de maio de 2020, a qual deixou ao alvedrio do DEPEN e dos demais órgãos da administração penitenciária a implementação de estruturas extraordinárias específicas. Entretanto, a Resolução $n^{\circ} 5$ determinou, em seu artigo $4^{\circ}$, alguns pressupostos básicos para as chamadas estruturas extraordinárias e vedou a utilização de contêineres ou outras estruturas similares para essa finalidade (BRASIL, 2020f).

Sobre os índices da COVID-19 nos presídios, conforme dados fornecidos pelo painel de monitoramento do DEPEN, até 31 de julho de 2020, foram realizados 33.463 testes para a detecção do novo coronavírus nas prisões brasileiras, os quais confirmaram 11.966 casos acumulados de pessoas infectadas nas unidades prisionais de todo o país, 7.334 recuperações, 3.104 suspeitas e 74 óbitos (BRASIL, 2020c, p. 2). Outrossim, é interessante pontuar que de todas as medidas utilizadas no combate à COVID-19, o painel de monitoramento do DEPEN apenas destaca a restrição ou suspensão total das visitas. Assim, até 31 de julho de 2020, as 26 unidades federativas do Brasil, o Distrito Federal e o Sistema Penitenciário Federal adotaram a suspensão total de visitas (BRASIL, 2020c, p. 4).

É importante lembrar que para amenizar os riscos de contágio da infecção por COVID-19, recomenda-se atentar para práticas de higiene frequentes, tais como lavar as mãos com água e sabão ou álcool em gel, além da aderência ao distanciamento social. Entretanto, a adoção desses hábitos acaba sendo inviabilizada em ambientes onde não há a possibilidade de distanciamento social, tampouco acesso a produtos de higiene básica, como é o caso de grande parte dos estabelecimentos penais do Brasil. Dessa forma, enquanto correm propostas e contrapropostas, as unidades prisionais seguem soerguendo índices preocupantes de contágio pelo novo coronavírus e torna-se cada vez mais relevante a análise do problema a partir dos impactos que a cultura do encarceramento exerce sobre a aplicação das medidas de combate antepostas na presente pesquisa.

\section{A CULTURA DO ENCARCERAMENTO COMO FATOR AGRAVANTE À PANDEMIA NAS PRISÕES}

Para guiar as discussões acerca de como o pensamento punitivista obsta o debate sobre o desencarceramento racional com vistas à prevenção da infecção por COVID-19 no âmbito dos estabelecimentos prisionais, torna-se essencial a menção de alguns dispositivos inseridos no ordenamento jurídico nacional que consolidam o direito à saúde das pessoas privadas de liberdade no Brasil, de modo que quaisquer atitudes que lesionem esse direito são verdadeiras afrontas a Constituição Federal de 1988.

Destarte, o artigo 196 da Magna Carta, ao dispor sobre o direito à saúde, expressa que esse se qualifica por ser um direito de todos e dever do Estado, não fazendo distinção de qualquer ordem quanto à concessão a tal direito, haja vista que o acesso à saúde deve ser universal e igualitário às ações e serviços para sua promoção, proteção e recuperação (BRASIL, 1988). Aliás, a Magna Carta também assevera, em seu artigo $5^{\circ}$, inciso XLIX, que é direito fundamental das pessoas privadas de liberdade o respeito à sua integridade física e moral e é com base nisso que a LEP determina, em seu artigo 41, inciso VII, que é direito do preso a assistência à saúde (BRASIL, 1984).

Nessa linha, o Código Penal, em seu artigo 38, expressa que "o preso conserva todos os direitos não atingidos pela perda da liberdade, impondo-se a todas as autoridades o respeito à sua integridade física e moral" (BRASIL, 1940). Assim, percebe-se que a distinção feita pelo ordenamento jurídico entre os indivíduos livres e os presos é justamente a privação de liberdade destes, não sendo justificáveis quaisquer medidas restritivas de direitos impostas à população encarcerada com vistas no fundamento da sua particular condição.

Embora a CF/1988 assegure aos presos o respeito a sua integridade física e moral, diante da realidade dos estabelecimentos penais brasileiros, tal garantia fundamental resta esquecida, fato que demonstra a incompetência do Poder Público em proteger, até mesmo, direitos fundamentais. Portanto, no atual cenário de calamidade pública causado pelo novo coronavírus, manter um indivíduo encarcerado em um estabelecimento superlotado, sem condições mínimas de higiene não pode configurar outra coisa que não seja o cumprimento de uma pena cruel, o que é expressamente vedado pela CF/1988, através de seu artigo $5^{\circ}$, inciso XLVI, alínea "e", o qual afirma que "não haverá penas cruéis" (BRASIL, 1988).

Isto posto, legitimar um sistema prisional desestruturado, incapaz de promover a reintegração social dos presos e egressos, torna-se um trabalho improfícuo tendo em vista a excepcionalidade da conjuntura atual, o que só pode ser justificado por um sentimento punitivista 
irracional, enraizado no âmbito social e jurídico, o qual entende ser a prisão uma resposta eficaz às inúmeras falhas institucionais e estruturais do Estado.

É nesse contexto que a cultura do encarceramento se insere como fator negativo ao combate do novo coronavírus nas prisões brasileiras, visto que ela desestimula e rejeita as ações de desencarceramento racional, propostas com a finalidade de reduzir a disseminação da COVID-19 nas unidades penais em que o mero isolamento é inviável diante da superpopulação carcerária.

Saliente-se que a cultura do encarceramento acentua desigualdades sociais e econômicas, ao passo em que as falhas institucionais e estruturais do Estado têm como resposta um rigor penal que só atinge as camadas mais pobres e excluídas socialmente, tendo em vista que a maior parte da população carcerária é composta por pessoas de baixa escolaridade e pretas e pardas (MOURA, 2017, p. 30-36). Assim sendo, a cultura do encarceramento é segregacionista e nega os problemas socioeconômicos do Brasil que são responsáveis por parte do aumento da criminalidade. Portanto, no atual cenário pandêmico, o direito à saúde de milhares de pessoas excluídas socialmente, as quais se encontram sob a tutela penal do Estado, é mitigado pelo discurso punitivista, o que perpetua o problema da superlotação do sistema penitenciário e, consequentemente, promove o agravamento de infecções entre os presos, como é o caso da doença causada pelo novo coronavírus.

À vista disso, na atual conjuntura, os ideais punitivistas tornam-se nefastos na medida em que prejudicam o desenvolvimento de um debate racional sobre a situação dos presos e impedem a visualização das prisões como um complexo sistema que envolve aspectos sociais e políticos, além de não levar em consideração os riscos aos quais se submetem os próprios agentes e profissionais desses sistemas punitivos.

Nesse sentido, nota-se que quando o sentimento punitivista migra para uma busca por respostas no âmbito judicial, este é o momento em que os magistrados devem revelar seus deveres garantistas em face do ordenamento jurídico, exercendo o "papel de garantidor dos direitos fundamentais do imputado" (JÚNIOR, 2020, p. 707).

Entretanto, a não adesão pelos magistrados das medidas de desencarceramento propostas pelo $\mathrm{CNJ}$, como forma de minimizar o contágio do coronavírus entre os indivíduos custodiados em estabelecimentos superlotados, revela a adoção de uma política negacionista por parte do Poder Judiciário. Nesse seguimento, faz-se pertinente concordar com Zaffaroni (1991, p. 83) quando este afirma que "negar um problema já existente, [...] não representa uma resposta real e, sim, a adoção de uma atitude histérica: ignoro o perigo e com isso suponho que ele desapareça".

Outrossim, ressalte-se que a indiferença direcionada à população prisional por vasto segmento da sociedade brasileira, aliada ao temor social de aumento da insegurança pública se houvesse o desencarceramento nos moldes da recomendação do CNJ, não se justifica quando são analisados certos aspectos quanto ao perfil dos indivíduos presos, do regime prisional no qual se encontram e das incidências por tipo penal. Além disso, quando se incentiva o debate acerca de medidas antipunitivistas como a forma mais lógica de oportunizar a prevenção da COVID-19 nos estabelecimentos penais brasileiros, os defensores do rigor penal afirmam, equivocadamente, que todos os estupradores e homicidas seriam soltos no convívio social ou apelam para o discurso da impunidade.

Entretanto, tais argumentos não se baseiam no texto da Recomendação do CNJ, mas sim na cultura do encarceramento, haja vista que os autores de crimes cometidos com violência ou grave ameaça à pessoa não estão comtemplados pela proposta de desencarceramento do CNJ. Assim, torna-se patente que essas alegações são meros pretextos para legitimar a rigidez do encarceramento, recorrendo à máxima da segurança pública e paz social, mesmo quando se busca mitigar o rigor da prisão para indivíduos que não oferecem perigo premente à convivência social.

Ademais, é de fundamental importância ressaltar a incompatibilidade jurídica de manter encarcerados os indivíduos presos provisoriamente, os quais correspondem a 29,75\% da população prisional (BRASIL, 2020b, p. 3). Frise-se que a prisão provisória está prevista no artigo 312 do Código de Processo Penal e tem como finalidade a tutela do processo, representando, por isso, uma espécie de medida cautelar que, como ensina Aury Lopes Júnior (2020, p. 637), deve estar pautada em "princípios que permitirão a coexistência de uma prisão sem sentença condenatória transitada em julgado com a garantia da presunção de inocência", destinando-se à tutela do processo.

É inconstitucional atribuir à prisão cautelar a função de controlar o alarma social, e, por mais respeitáveis que sejam os sentimentos de vingança, nem a prisão preventiva pode servir como pena antecipada e fins de prevenção, nem o Estado, enquanto reserva ética, pode assumir esse papel vingativo. (JÚNIOR, 2020, p. 704)

Dito isto, o forte apelo popular contra a impunidade fantasiosa e seletiva no seio social transfigurase na banalização do dispositivo da prisão provisória como um sustentáculo do encarceramento em massa. Portanto, há um expressivo número de pessoas que não foram condenadas pelo sistema de justiça formal, presumidamente inocentes em termos constitucionais, mas que se convencionou, tacitamente, que os manter 
encarcerados em um momento de pandemia seria uma política criminal eficaz para conservar a harmonia social e não destoar do discurso seletivo que predomina nas bases do sistema penal.

Diante do exposto, resta evidente que, a urgência na tomada de medidas preventivas contra a disseminação da infecção causada pela COVID-19, não se apresenta tão urgente no sistema carcerário, o que desmascara as reais finalidades do discurso jurídico-penal e da própria pena, que cumpre, dado o contexto hodierno, o papel de excepcionar o indivíduo privado de sua liberdade e sob tutela do Estado, de seus direitos e garantias fundamentais, constitucionalmente previstos, aliado ao discurso conservador sobre a prisão que tenta camuflar uma realidade ostensiva e tão presente, além de acentuar as desigualdades presentes na estrutura social do Brasil e promover a segregação dos encarcerados.

\section{CONCLUSÃO}

Tendo por base as discussões ora expostas, conclui-se que a cultura do encarceramento se apresenta não como um obstáculo propriamente dito, mas como um fator desfavorável ao combate e à prevenção do novo coronavírus nas prisões. Nesse contexto, dada à realidade do sistema prisional brasileiro, cuja característica mais latente é a superlotação que, por si só, é fator agravante à transmissão de infecções entre as pessoas privadas de liberdade, percebe-se que as medidas do Poder Público que não sejam direcionadas ao desencarceramento racional da população carcerária, configuram atitudes negligentes e negacionistas da gravidade do problema a ser enfrentado.

Ademais, o presente estudo constatou que a cultura do encarceramento se materializa, por exemplo, na rigidez da manutenção do indivíduo em regime de prisão privativa de liberdade, mesmo que ele se enquadre na recomendação do $\mathrm{CNJ}$. Isto posto, a manutenção da superpopulação prisional é legitimada pela cultura do encarceramento, não obstante o a crise de saúde pública presente no Brasil. Além disso, evidenciou-se que os ideais punitivistas fundamentam-se em argumentos destituídos de veracidade, os quais buscam perpetuar uma situação de sucessivas agressões aos direitos e garantias das pessoas privadas de liberdade, realçando desigualdades e fomentando a segregação na sociedade brasileira.

Portanto, embora as discussões acerca do tema não se esgotem, pode-se inferir que a excepcionalidade da situação enfrentada pelos presídios brasileiros, referente à pandemia do coronavírus, apenas confirma a regra presente na sistemática penal brasileira: a inviabilização dos presos e o cumprimento, por estes, de uma pena mais severa do que a permitida pela legislação de um país tal qual o Brasil, que se afirma um Estado Democrático de Direito.

\section{REFERÊNCIAS}

BITENCOURT, Cezar Roberto. Tratado de Direito Penal, Volume 1: parte geral (arts. $1^{\circ}$ a 120$)$. 26. ed. São Paulo: Saraiva Educação, 2020. 1072 p.

BRASIL. Constituição (1988). Constituição da República Federativa do Brasil. Brasília, DF, 05 out. 1988.

Decreto Legislativo $\mathrm{n}^{\circ}$ 6, de 6 de julho de 2020. Reconhece, para os fins do art. 65 da Lei Complementar $\mathrm{n}^{\circ} 101$, de 4 de maio de 2000, a ocorrência do estado de calamidade pública, nos termos da solicitação do Presidente da República encaminhada por meio da Mensagem $n^{\circ} 93$, de 18 de março de 2020. Diário Oficial da União, seção 1, Brasília, DF, ano 158, n. 55-C, p. 1, 20 mar. 2020a.

Decreto-lei $\mathrm{n}^{\mathbf{0}}$ 2848, de 07 de dezembro de 1940. Código Penal. Brasília, DF, 07 dez. 1940.
Departamento Penitenciário Nacional. Ministério da Justiça e Segurança Pública (org.). Levantamento Nacional de Informações Penitenciárias: atualização dezembro de 2019. Brasília: Ministério da Justiça e Segurança Pública, 2020b.

Departamento Penitenciário Nacional. Ministério da Justiça e Segurança Pública. Medidas de Combate ao COVID-19: painéis de monitoramento. Brasília: Ministério da Justiça e Segurança Pública, 2020c. Disponível

em: https://app.powerbi.com/view?r=eyJrIjoiYThhMjk5Yjgt ZWQwYS00ODlkLTg4NDgtZTFhMTgzYmQ2MGVlIi widCI6ImViMDkwNDIwLTQ0NGMtNDNmNy05MW YyLTRiOGRhNmJmZThlMSJ9. Acesso em: 31 jul. 2020.

Departamento Penitenciário Nacional. Ministério da Justiça e Segurança Pública. Estruturas e Instalações Temporárias Sistema Prisional: enfrentamento da pandemia covid-19, abril de 2020. Brasília: Ministério da 
Justiça e Segurança Pública, 2020d. 36 p.

. Lei $\mathrm{n}^{\circ} 13.979$, de 06 de fevereiro de 2020. Dispõe sobre as medidas para enfrentamento da emergência de saúde pública de importância internacional decorrente do coronavírus responsável pelo surto de 2019. 27. ed. Diário Oficial da União, seção 1, Brasília, DF, ano 158, n. 27, p. 1, 07 fev. 2020e.

Lei $\mathbf{n}^{\mathbf{0}}$ 7.210, de 11 de julho de 1984. Institui a Lei de Execução Penal. Brasília, DF, 11 dez. 1984.

Ministério da Justiça e Segurança Pública. Conselho Nacional de Política Criminal e Penitenciária. Resolução $\mathrm{n}^{\circ}$ 5, de 05 de maio de 2020. Dispõe sobre Diretrizes Extraordinárias e Específicas para Arquitetura Penal, destinadas para o enfrentamento da disseminação do novo Coronavírus (2019-nCoV) no âmbito dos estabelecimentos penais. 94. ed. Diário Oficial da União, seção 1, Brasília, DF, ano 158, n. 94, p. 38-39, 19 mai. $2020 \mathrm{f}$.

Ministério da Justiça e Segurança Pública. Portaria Interministerial $\mathrm{n}^{\circ} 7$, de 18 de março de 2020. Dispõe sobre as medidas de enfrentamento da emergência de saúde pública previstas na Lei ${ }^{\circ} 13.979$, de 6 de fevereiro de 2020, no âmbito do Sistema Prisional. 53-B. ed. Diário Oficial da União, seção 1, Brasília, DF, ano 158 , n. 53-B, p. 1,18 mar. 2020g.

Ministério da Justiça e Segurança Pública. Portaria $\mathrm{n}^{\circ} 188$, de 03 de fevereiro de 2020. Declara Emergência em Saúde Pública de importância Nacional (ESPIN) em decorrência da Infecção Humana pelo novo Coronavírus (2019-nCoV). 24-A. ed. Diário Oficial da União, seção 1, Brasília, DF, ano 158, n. 24-A, p. 1, 04 fev. 2020h.

CONSELHO NACIONAL DE JUSTIÇA - CNJ. Recomendação n⿳ 62, de 17 de março de 2020. Brasília, DF: Conselho Nacional de Justiça, 2020.

JESUS, Damásio de. Direito penal, volume 1: Parte geral. Atualização de André Estefam. 37 ed. São Paulo: Saraiva Educação, 2020. 764 p.

JÚNIOR. Aury Lopes. Direito Processual Penal. 17. ed. São Paulo: Saraiva Educação, 2020. 1232 p.

MACHADO, Ana Elise Bernal; SOUZA, Ana Paula dos Reis; SOUZA, Mariani Cristina de. Sistema Penitenciário Brasileiro - Origem, Atualidade e Exemplos Funcionais. Revista do Curso de Direito, [s.1.], v. 10, n. 10, p. 201212, $31 \mathrm{dez}$. 2013. Instituto Metodista de Ensino Superior. http://dx.doi.org/10.15603/2176-1094/rcd.v10n10p201212.

MOURA, Marcos Vinícius (org.). Departamento Penitenciário Nacional. Ministério da Justiça e Segurança Pública. Levantamento Nacional de Informações Penitenciárias: atualização junho de 2017. Brasília: Ministério da Justiça e Segurança Pública, 2019. 87 p.

NUCCI, Guilherme de Souza. Curso de Execução Penal. 2. ed. Rio de Janeiro: Forense, 2019. 1397 p.

SÃO PAULO (Estado). Coordenação de Pesquisas da Defensoria Pública de São Paulo. In: SÃO PAULO (Estado). Painel interativo. São Paulo: [s.n.], 2020. Disponível em: https://www.defensoria.sp.def.br/dpesp/Conteudos/Notici as/NoticiaMostra.aspx ?idItem=89767\&idPagina=3086.

Acesso em: 31 jul. 2020.

ZAFFARONI, Eugenio Raul. Em busca das penas perdidas: a perda de legitimidade do sistema penal. Rio de Janeiro: Revan, 1991. 